\title{
Experiências de estudantes em cálculo 1
}

DOI 10.26512/Ic.v25i0.23172

\author{
Sonia Maria da Silva Junqueira ${ }^{1}$ \\ Ana Lúcia Manrique ${ }^{2}$
}

\section{Resumo}

Este artigo tem como objetivo apontar possibilidades de experiências de estudantes em aulas de Cálculo 1, especificamente em relação ao conteúdo Derivada. As escolhas teóricas foram conduzidas em torno da relação dialógica e da dimensão da experiência como campos de subjetividades no qual se assenta a problemática do Cálculo 1. Delineou-se uma análise de conteúdo com aspectos interpretativos e descritivos por meio dos quais se constituiu este estudo junto a 186 estudantes de cursos de Engenharias e Licenciaturas matriculados em uma Universidade Pública Federal. A coleta de dados que ora se destaca ocorreu em abordagens reveladoras de hipóteses subjetivas identificáveis a partir dos relatos dos sujeitos investigados. Concluiu-se que a experiência em aulas de Cálculo 1 tem sentidos de reciprocidade na ação de mão dupla que engloba conteúdos e sujeitos da experiência; de unicidade, pela subjetividade e identidade de cada sujeito; de imprevisibilidade, pelas incertezas, perigos e possibilidades da experiência; de temporalidade, pois prescinde o reconhecimento de tempos e espaços distintos aos sujeitos da experiência. Os sujeitos investigados deixaram transparecer aspectos aparentemente contraditórios que, todavia, denotaram complementaridades. Os estudantes revelaram emoções, sentimentos, angústias, mostraram-se incipientes, revelando marcas das experiências que se consolidam na relação que se estabelece em aulas de Cálculo 1.

Palavras chave: Experiência. Relação dialógica. Estudantes de Cálculo 1.

1 Doutora em Educação Matemática pela PUC/SP. Programa de Pós-Graduação em Ensino - Unipampa, soniajunqueira@unipampa.edu.br.

2 Doutora em Educação pela PUC/SP. Programa de Pós-Graduação em Educação Matemática - PUC/SP. analuciamanrique@gmail.com 


\section{Abstract}

This article aims to point out possibilities of student experiences in Calculus 1 classes, specifically in relation to Derivative content. The theoretical choices were made around the dialogical relationship and the dimension of experience as fields of subjectivity on which the problem of Calculus 1 is based. A content analysis was elaborated with interpretative and descriptive, through which this study with 186 students of engineering and undergraduate courses, enrolled in a Federal Public University. The collection of data that now stands out occurred in approaches revealing subjective hypotheses identifiable from the reports of the subjects investigated. It was concluded that the experience in Calculus 1 classes has reciprocity senses, in the double-hand action that encompasses objects and subjects of experience; of uniqueness, by the subjectivity and identity of each subject; unpredictability, uncertainties, dangers and possibilities of experience; of temporality, since it ignores the recognition of times and spaces distinct from the subjects of experience. The subjects investigated reveal apparently contradictories, which, however, denoted complementarities. The students demonstrate emotions, feelings, torment, were incipients, revealing marks of experiences that are consolidated in the relation that is established in Calculus 1 classes.

Keywords: Experience. Dialogical Relation. Calculus 1 students. 


\section{Resumen}

Este artículo tiene como objetivo apuntar posibilidades de experiencias de estudiantes en clases de Cálculo 1, específicamente en relación al contenido Derivada. Las elecciones teóricas fueron conducidas en torno a la relación dialógica y de la dimensión de la experiencia, como campos de subjetividades en las que se asienta la problemática del Cálculo 1. Delineado un análisis de contenido con aspectos interpretativos y descriptivos, por medio de los cuales se constituyó éste estudio junto a 186 estudiantes de cursos de Ingenierías y Licenciaturas, matriculados en una Universidad Pública Federal. La recolección de datos que se destaca se ha producido en enfoques reveladores de hipótesis subjetivas identificables a partir de los relatos de los sujetos investigados. Se concluyó que la experiencia en clases de Cálculo 1 tiene sentidos de reciprocidad, en la acción de doble mano que engloba contenidos y sujetos de la experiencia; de unicidad, por la subjetividad e identidad de cada sujeto; de imprevisibilidad, de incertidumbres, peligros y posibilidades de experiencia; de temporalidad, pues prescinde el reconocimiento de tiempos y espacios distintos a los sujetos de la experiencia. Los sujetos investigados dejaron transparentes aspectos aparentemente contradictorios, que, sin embargo, denotaron complementariedades. Los estudiantes revelaron emociones, sentimientos, angustias, se mostraron incipientes, revelando marcas de las experiencias que se consolidan en la relación que se establece en las clases de Cálculo 1.

Palabras clave: Experiencia. Relación dialógica. Estudiantes de Cálculo 1. 


\section{Résumé}

Cet article a pour but de mettre en évidence les possibilités d'expérience des élèves dans les cours de calcul 1, en particulier en ce qui concerne le contenu dérivé. Les choix théoriques ont été faits autour de la relation dialogique et de la dimension de l'expérience en tant que champs de subjectivité sur lesquels est basé le problème du calcul 1. Une analyse de contenu a été élaborée avec les aspects interprétatif et descriptif étudier avec 186 étudiants en ingénierie et de premier cycle, inscrits dans une université publique fédérale. La collecte de données qui se dégage maintenant a été effectuée dans le cadre d'approches révélant des hypothèses subjectives identifiables à partir des rapports des sujets étudiés. II a été conclu que l'expérience dans les classes de calcul 1 avait des sens de réciprocité, dans l'action à double main qui englobe le contenu et les sujets de l'expérience; de l'unicité, par la subjectivité et l'identité de chaque sujet; imprévisibilité, incertitudes, dangers et possibilités d'expérience; temporalité, car elle ignore la reconnaissance de temps et d'espaces distincts des sujets de l'expérience. Les sujets étudiés ont révélé des aspects apparemment contradictoires, qui dénotaient toutefois des complémentarités. Les élèves ont révélé des émotions, des sentiments, des angoisses, ils étaient naissants, révélant des marques d'expériences consolidées dans la relation établie dans les classes de calcul 1.

Mots-clés: Expérience. Relation de dialogue. Etudiants de Calcul 1.

\section{A escolha pelo Cálculo 1}

Esse artigo tem como objetivo apontar possibilidade de "Experiência" de estudantes em aulas de Cálculo 1, especificamente nos processos de construção do conhecimento da Derivada. A escolha pelo Cálculo 1 é devida, em parte, pela constatação de que em grande número de cursos em que essa disciplina é ministrada ocorre certa recorrência, seja na forma como é ministrada, na abrangência dos objetivos geral e específicos, ou na linearidade dos conteúdos. Tais aspectos foram confirmados em levantamento inicial realizado a partir da análise de Planos de Ensino de Cálculo 1 de diferentes universidades públicas e privadas brasileiras (JUNQUEIRA; MANRIQUE, 2012).

O componente curricular Cálculo Diferencial e Integral, em sua constituição histórica, parece manter uma estrutura solidificada no sentido dado por Bauman (2001), com uma abordagem metodológica fortemente favorecida por elementos da racionalidade técnica sob a qual se verifica uma espessa massa de estudantes reprovados. Assim, mostra-se inserido em um contexto pedagógico e institucional que pouco se modificou 
ao longo de décadas, mantendo sua forma inalterada (JUNQUEIRA, 2010). Embora revele explicitamente em seus próprios resultados, corroborados por pesquisas (Barufi, 1999; Rezende, 2003; Dall'Anese, 2006; Vieira, 2013), a necessidade de alguma ação transformadora, parece obstinado a permanecer com a mesma composição inicial, solidificando-se ao longo dos tempos.

Nesse contexto, estudos exploratórios baseados em Reis (2001); Silva (2011); Garzella (2013) apontaram especialmente os altos índices de reprovação, de evasão e de queixas dos estudantes em relação às dificuldades encontradas ao cursarem essa disciplina. A existência de conflitos indicou que estão em campo identidades que devem ser respeitadas e que alcançar o conhecimento de um objeto matemático requer o diálogo entre essas identidades; diálogo esse, que leva à Experiência os envolvidos nesse processo de construção do conhecimento e de saberes em jogo.

\section{Relação dialógica e experiência}

A relação dialógica compreende a relação de reciprocidade, entendida como um compartilhar em mão dupla, que não acolhe apenas um encontro impessoal e desprovido de afetividade, pois ocorre em meio da intrincada interação entre sujeitos e objeto.

Concorda-se que a dialogicidade é uma questão básica para a abordagem sociocultural; e que a relação professor - aluno - instituição - conteúdo deveria ser horizontal, com o objetivo de desenvolvimento de uma consciência crítica e libertadora (FREIRE, 1979), que valorize a linguagem pela qual os elementos dessa relação procuram a superação da consciência ingênua para a percepção das contradições sociais.

Em especial, interessa nesta investigação a relação dialógica entre os envolvidos no processo ensino-aprendizagem da Derivada e a experiência (LARROSA, 2011) dos estudantes em aulas de Cálculo 1. Reconhece-se que o caráter multifacetado da disciplina de Cálculo 1 deva afetar não apenas a vida acadêmica dos estudantes (BAUMAN; MAY, 2010), mas também as expectativas destes e de seus professores, e de forma nem sempre positiva. Acredita-se que em algum momento os sujeitos que passaram por essa disciplina possam dar pistas de como aconteceu essa passagem e das implicações nos processos de sua formação. Assim, admite-se que é a partir de um processo de interação que sujeitos são capazes de ser transformados ou modificados, e que o sujeito se dá a conhecer, e conhece o novo.

Contribuem nessa altercação sobre a relação dialógica Bauman e May (2010), pois revelam que a sociologia poderia fornecer observações sobre as experiências humanas e mostrar as implicações de atos e decisões que conduzem a vida do homem. 
No dizer desses autores, pensar sociologicamente significa entender os outros, em suas esperanças, desejos, inquietações e preocupações, em um constante sentido de alteridade. Ademais, refletem sobre o modo como a sociologia pode contribuir objetivamente para a vida humana, uma vez que estabelece limites, molda perspectivas, desenha opções, e também ressalta impossibilidades. Assim, cada um é um ator habilidoso cujas realizações e o que se é, dependem do que fazem os outros.

Nessa relação em que se estabelecem os processos educativos, a liberdade é sempre limitada a fatores internos ou externos à ação pedagógica. Todavia, quando um indivíduo consegue transformar-se a partir dessa relação que é essencialmente dialógica, nisso consiste a autêntica liberdade do encontro mútuo entre o ser e o saber. Contudo, Baumam e May (2010) admitem que, o que envolve a capacidade de alterarse ou modificar-se diante das próprias competências pode não ter relação com a busca por atingir metas, e reforçam que nem sempre o resultado depende exclusivamente de si. "Nem todas as pessoas que buscam os mesmos objetivos conseguem conquistálos, porque o número de recompensas disponíveis é limitado" (BAUMAM; MAY, 2010, p. 35).

Nesse sentido, vive-se em constante interação com os outros e livres para escolher e seguir essas escolhas até o fim; no entanto, nem sempre essas são decisões conscientes. Em muito, decorrem de hábitos e, de modo similar, evita-se quebrar regras que em geral orientam não só as ações, mas a forma como essas são coordenadas com as ações de outras pessoas, que podem antecipar atitudes em diversas situações. Desse modo, uma coisa é ter a habilidade de alterar ou modificar competências; outra, muito diferente, é ser capaz de alcançar as metas almejadas, para o que é preciso mais do que o livre arbítrio quando se vivencia essa experiência.

No âmbito da experiência, Larrosa (2011, p. 2) pronuncia: "[...] a experiência é isso que me passa [...]", expondo um resgate ou o que se pode chamar de ressignificação da experiência. Menciona o uso e abuso dessa palavra em Educação, que é quase sempre empregada de forma banalizada, sem a consciência de suas possibilidades teóricas, críticas e práticas. E com relação ao "isso" da frase pronunciada, apresenta o princípio da alteridade, significando que não há experiência sem a presença do outro, ou de um algo, ou de um isso, de um acontecimento definitivo ou exterior ao Eu. A experiência não reduz o acontecimento, mas o sustenta como irredutível. Sua justificativa para o "me", da mesma frase, leva ao princípio da reflexividade, subjetividade, transformação. A experiência supõe que um acontecimento exterior ao Eu, ao passar, não se coloque apenas diante do Eu, mas o atravesse e deixe sua marca.

A experiência supõe, como já afirmei, um acontecimento exterior a mim. Mas o lugar da experiência sou eu. É em mim (ou em minhas palavras, ou em minhas ideias, ou em minhas representações, ou em meus sentimentos, ou em meus projetos, ou em minhas intenções, ou em meu saber, ou em meu poder, ou em minha vontade) onde se dá a experiência, onde a experiência tem lugar (LARROSA, 2011, p. 6). 
A experiência se dá porque esse sujeito sensível, vulnerável e ex/posto é um sujeito aberto a sua própria transformação. É, portanto, o Eu, o lugar da experiência.

E com relação ao "passar", a experiência é um passo, uma passagem, um percurso. Se a palavra experiência tem o ex de exterior, tem também o per, com significado de travessia, passagem, caminho, viagem. A experiência supõe uma saída de si para outra coisa, como se fosse uma passagem para o isso, para esse território de insegurança, de perigo e de incerteza.

Se a experiência é "isso que me passa", o sujeito da experiência é como um território de passagem, como uma superfície de sensibilidade em que algo passa e que "isso que me passa", ao passar por mim ou em mim, deixa um vestígio, uma marca, um rastro, uma ferida. (LARROSA, 2011, p. 5).

Daí ressalta que o sujeito da experiência não é, em princípio, um sujeito ativo, um agente de sua própria experiência, mas um sujeito paciente, passional; contudo, não é passivo, pois não fica indiferente à passagem, pois é atravessado por ela.

A experiência também não diz respeito à prática, embora se admita que a prática possa dar lugar à experiência. A experiência é singular, o que quer dizer que, para cada sujeito ela é única. A experiência supõe o princípio da irrepetibilidade e da pluralidade. Um experimento tem que ser repetido, considerando sempre as mesmas variáveis; ao contrário, a experiência é irrepetível. É também plural, mesmo sendo singular, pois representa soma de singularidades. A experiência supõe liberdade, uma vez que o sujeito da experiência não depende da tutela de outrem, e nessa relação se liga a incertezas, pois, sentir-se livre é não ter certeza do resultado de um acontecimento. Nesse aspecto, o sujeito da experiência em aulas de Cálculo 1 experimenta e experiencia, porque no momento do experimento repete procedimentos, métodos, regras. No instante da experiência, é atravessado pelo conhecimento de fato.

\section{Métodos}

Aportou-se a metodologia em uma perspectiva qualitativa (BOGDAN; BIKLEN, 1994), conduzida por meio de uma Análise de Conteúdo (BARDIN, 2009). A partir das análises realizadas, a investigação destacou quatro unidades textuais, nomeadas em: O estudante e sua formação básica; O professor de cálculo 1; O estudante e a instituição; e $O$ estudante e o cálculo 1. E três categorias para mapas conceituais, estruturadas em: Regras de derivação; Conceito da derivada; e Aplicação da derivada (JUNQUEIRA, 2014).

Neste recorte, especificamente serão consideradas as unidades textuais: $O$ estudante e sua formação básica; O professor de cálculo 1; O estudante e a instituição; e O 
estudante e o cálculo 1, obtidas a partir dos relatos dos sujeitos investigados, quando solicitados a comentar sobre a disciplina de Cálculo 1, e a comentar sobre seu desempenho nesta disciplina.

Cabe destacar que a amostra contou com um número de 186 estudantes matriculados nos respectivos quantitativos e cursos, sendo (13) na Engenharia de Alimentos (EA); (13) na Engenharia de Computação (EC); (41) na Engenharia de Produção (EP); (13) na Engenharia de Energias Renováveis e de Ambiente (ER); (50) na Engenharia em Química (EQ); (10) na Licenciatura em Física (LF); (39) na Licenciatura em Matemática (LM); e (07) na Licenciatura em Química (LQ). A Instituição pesquisada, um dos campi de uma universidade pública brasileira, foi instituída a partir do programa de expansão das universidades federais no Brasil. A seguir, apresenta-se no quadro 1 os resultados gerais do componente de Cálculo 1 no período de 2009 a 2012 para os cursos mencionados.

Quadro 1 - Resultados gerais em aprovação e reprovação em Cálculo 1, dos cursos investigados, no período de 2009/Sem.1 a 2012/Sem.1.

\begin{tabular}{|l|l|l|l|l|l|l|l|l|}
\hline CÁLCULO 1 & 2009 & 2009 & 2010 & 2010 & 2011 & 2011 & 2012 & $\begin{array}{l}\text { Total no } \\
\text { período }\end{array}$ \\
\hline No de Aprovados & 95 & 32 & 87 & 105 & 79 & 79 & 108 & 585 \\
\hline \% de Aprovados & 49,48 & 32,32 & 28,62 & 52,5 & 24,01 & 44,63 & 26,93 & 45,73 \\
\hline$N^{\circ}$ de Reprovados & 97 & 67 & 217 & 95 & 250 & 98 & 293 & 1117 \\
\hline \% de Reprovados & 50,52 & 67,68 & 71,38 & 47,5 & 75,99 & 55,37 & 73,07 & 85,86 \\
\hline Total parcial (TP) & 192 & 99 & 304 & 200 & 329 & 177 & 401 & 1702 \\
\hline \% sobre TP & 11,28 & 5,82 & 17,86 & 11,75 & 19,33 & 10,4 & 23,56 & 100 \\
\hline
\end{tabular}

Fonte: Dados Intitucionais em (JUNQUEIRA, 2014, p. 80)

A respeito dos dados sobre a amostra e do apresentado no quadro 1, nota-se nos sete semestres considerados no período que Cálculo 1 foi ministrado para uma média de 243 alunos por semestre. Entende-se como relevante apontar esses dados a fim de apresentar uma comparação plausível acerca do número de estudantes considerados na amostra deste trabalho, pois embora os sujeitos não sejam estudantes de um mesmo semestre no componente de Cálculo 1, o número de 186 sujeitos que aceitaram o convite para participar desta pesquisa é significativo.

A fim de garantir o sigilo nos fragmentos dos relatos, os sujeitos investigados foram 
identificados pelas iniciais de seus cursos, pelo seu número de classificação na lista de cada curso e pelo número da abordagem comentada. Assim, o sujeito (LM028/ AB2) é o sujeito de número 28 na classificação dos estudantes da Licenciatura em Matemática que teceu comentário sobre a abordagem 2, que segue descrita a seguir. Cabe destacar que todos os sujeitos participantes foram convidados a participar da pesquisa e se colocaram como voluntários.

O instrumento para produção dos dados de pesquisa foi estruturado de forma a conter abordagens abertas, previamente definidas, porém capazes de remeter os sujeitos pesquisados a uma relação informal sobre a temática abordada, e que não os limitassem acerca das discussões remetidas em seus textos. Desse modo, para essa etapa textual foram consideradas as seguintes abordagens:

Abordagem 1 - Comente sobre a disciplina de Cálculo 1. Essa abordagem é apresentada aos estudantes a fim de que teçam, a partir de suas memórias, comentários relativos à disciplina de Cálculo 1. "Falem da disciplina";

Abordagem 2 - Comente sobre seu desempenho na disciplina de Cálculo 1. Nessa abordagem é solicitado que os sujeitos apresentem elementos que remetam ao seu próprio desempenho na disciplina de Cálculo 1. "Falem de si".

Com base nas análises realizadas em Junqueira (2014), apresenta-se a seguir a descrição sintetizada das unidades de análise textuais.

\section{Resultados e Análise}

Apresenta-se na continuidade, a síntese dos resultados e análises realizadas em Junqueira (2014), com uma breve descrição das unidades de análise textuais: 0 estudante e o ensino médio, O estudante e o professor de Cálculo 1, O estudante e a Instituição; e O estudante e o Cálculo 1.

\section{O estudante e o Ensino médio}

Essa unidade tomou sua forma devido à recorrência da expressão Ensino Médio nos relatos dos estudantes. Mesmo não sendo esses solicitados a comentar sobre o Ensino Médio em momento algum da pesquisa. Assim, um dos principais motivos das inúmeras dificuldades encontradas ao longo da passagem pelo Cálculo 1 e, consequentemente do baixo desempenho dos estudantes, é apontada nesta investigação como a defasagem que tais sujeitos admitem ter em relaçãoàmatemática 
estudada no Ensino Médio. Dos 186 sujeitos pesquisados, 76 mencionaram a possibilidade de terem cursado um Ensino Médio deficitário, quando solicitados a comentar sobre a disciplina de Cálculo 1. Destaca-se a seguir, a força negativa dessa suposta deficiência que parece perpetuar-se ao longo do curso, evidenciada na afirmação explicitada em um dos relatos.

Mas as minhas dificuldades provinham das deficiências do Ensino Médio, tornando tudo muito novo. Acredito que mesmo que essa disciplina já tenha sido superada, algumas dificuldades ainda persistam (LM028/AB2).

Posturas como essas colocam os sujeitos diante da representação que fazem da própria formação e que parece não ser favorável ao seu desenvolvimento no curso, e diante da qual se pronunciam, dão justificativas, e apresentam suas fugas e formas de contornar ou de tentar resolver o problema.

O meu desempenho não foi muito satisfatório, pois nunca tinha visto nada sobre cálculo diferencial, ou seja, minha base não era boa o suficiente para fazer uma disciplina de Cálculo I bem feita. Precisei rever vários conceitos básicos (EP022/AB2).

Os relatos de alguns sujeitos mostraram a defasagem do Ensino Médio como um dificultador de sua passagem pelo Cálculo 1; por outro lado, há argumentos pelos quais alguns admitem ter encontrado no Ensino Médio a base matemática necessária para cursar a disciplina de Cálculo 1. Embora esse tenha sido um número relativamente pequeno em comparação aos que tomaram posição contrária, cabe destacar que existe esse número para os quais a preparação em nível médio foi suficiente, e portanto, manter revisões intermináveis de conteúdos poderia ser um dispositivo desnecessário e desmotivador para esses estudantes.

Graças a uma base forte de matemática, tive facilidade em aprender os conteúdos de Cálculo I, sem ter estudado tanto, passei com uma média acima de 7,0 (EQ036/AB2).

Contudo, não se pode garantir que essa defasagem ocorra em razão de alguma precariedade em nível médio, embora os conteúdos apontados como deficitários pelos sujeitos estejam ligados à fundamentação em Funções, ou seja, a um conteúdo estudado com ênfase no Ensino Médio. Assim como não se pode deixar de considerar que, se existe tal defasagem, talvez ela possa ser anterior a essa etapa da Educação Básica.

Em relação a essas defasagens, os estudantes mencionaram a importância de ações como cursos de nivelamento para seu desenvolvimento em Cálculo 1, no entanto, a evasão dos estudantes nessas experiências tem sido recorrente na universidade investigada. 
A primeira vez que eu fiz foi um "choque", pois havia muita coisa do Ensino Médio e Fundamental, eu já não lembrava mais, só consegui obter êxito na disciplina após fazer um curso de nivelamento fora da universidade (ER003/AB2).

Admite-se que a dificuldade desses estudantes em relação ao Cálculo 1 possa estar em Matemática , mas não em um conteúdo específico, imediato, pontual, como um elemento em aberto em uma sequência de conteúdos, proposta por vezes como um caminho pelo qual se espera conduzir o sujeito da aprendizagem para alcançar um conhecimento matemático novo, maior, "superior".

Assim, algo mais pode estar dificultando essa "passagem" e impossibilitando aos estudantes 'a experiência (LARROSA, 2011) do encontro com o conhecimento novo em Cálculo 1. Seja esta ir além de sua forma atual, de mudar de forma em decorrência desse conhecimento novo e possível em aulas de Cálculo 1. Nesse sentido, a imprevisibilidade e a incerteza estão sempre presentes. Questiona-se como ou quais as experiências individuais parecem marcar a tentativa de superação desses estudantes.

Na primeira vez que fiz Cálculo I senti dificuldade por ter tido um Ensino Médio fraco, pois na parte de funções não tive um aproveitamento muito bom. Já na parte de limites e Derivadas acabei por dominar até bem a matéria, mas como não tinha ido bem na primeira parte acabei não passando. Na segunda vez fui atrás de livros para me ajudar a entender a parte de funções, desse jeito consegui passar, mas tive que me esforçar muito (ER005/AB2).

Mas se por ora a formação básica possa estar comprometida, e nesse momento não se tem interesse em abalizar motivos ou indicar culpados, é contudo urgente resgatála para a continuidade dos processos educativos. Aponta-se que a forma como o sujeito busca suprir a deficiência nessa formação deve estar em conformidade às suas necessidades e possibilidades, seja para a participação em atividades promovidas pela Instituição, ou professores ou ainda a partir de recursos pessoais de busca para o autoconhecimento, uma construção autônoma.

O sujeito da experiência tem algo desse ser fascinante que se expõe atravessando um espaço indeterminado e perigoso, pondo-se nele à prova e buscando nele sua oportunidade, sua ocasião. (LARROSA, 2011, p. 25).

Discorda-se, veementemente, de que a falta de base seja a razão para que futuros profissionais sejam submetidos a uma formação simplificada, reduzida em sua abrangência e que não gere a necessária transformação dos sujeitos. Discorda-se, ainda, de que os sujeitos sejam submetidos a uma formação que não produza um profissional qualificado e competitivo para os desafios da contemporaneidade. Contudo, com a mesma intensidade, não se pode aceitar que ao final de anos em processo de formação, tantos sujeitos revelem insegurança e insuficiência em relação a um conteúdo que se coloca historicamente como de significativa relevância à formação desses futuros profissionais. 


\section{O estudante e o professor de Cálculo 1}

Dois aspectos distintos marcam a forma como os estudantes investigados veem o professor de Cálculo 1. O primeiro, apresentado muitas vezes em tom de desabafo, colocando o professor na posição de um "algoz", cujas exigências e atitudes são qualificadas como desumanas ou responsáveis pelas reprovações e abandonos na disciplina de Cálculo 1, devido sobretudo ao que consideram "falta" de didática e metodologia. Já o segundo, apresenta a figura do "bom professor de Cálculo 1", aquele que com ótima metodologia e didática é o responsável pelo estudante conseguir entender a disciplina com coerência e perceber a relação entre os conteúdos, assim como sua aplicabilidade.

A alusão à figura do professor destacando esses aspectos aparece tanto na abordagem 1 quanto na abordagem 2, no entanto, nas duas abordagens os sujeitos não foram solicitados a comentar sobre seus professores de Cálculo 1.

Desisti 2 vezes, pois não pratiquei o conteúdo e não aprendi o conteúdo proposto pelo professor, ficando desmotivado: Quando peguei um professor com uma didática diferenciada aprendi o conteúdo e passei (EC005/AB1).

É possível notar que os sujeitos ao encontrarem algo de negativo em sua passagem pelo Cálculo 1 demonstram, explícita ou implicitamente, que tal fato está ligado essencialmente ao professor que ministrava a disciplina. Nesse sentido, observa-se uma responsabilização colocada pelo estudante exclusivamente sobre o professor e, por conseguinte, a retirada da responsabilidade do estudante nessa passagem. Contudo, Bauman e May (2010) contribuem ao mencionar do que pode depender a escolha de ação de uma pessoa livre para assumir responsabilidades. Há muitas situações em que a liberdade para agir é limitada por circunstâncias das quais não se tem o controle, por exemplo, em uma relação estabelecida de forma vertical entre professor e aluno, a liberdade de escolha é comprometida e um dos lados é de fato o mais responsável.

Assim, enquanto todas as pessoas são livres e não podem ser outra coisa senão livres - elas são obrigadas a assumir responsabilidade por tudo que fizerem -, algumas são mais livres que outras, porque seus horizontes e escolhas de ação são mais amplos, e elas, por outro lado, podem depender da restrição dos horizontes de outros (BAUMAM; MAY, 2010, p. 48).

Outro fator a ser considerado diz respeito ao que se pode chamar de "didática do professor de Cálculo 1". Um número significativo de estudantes relacionou o bom professor com a proposição de listas de exercícios, uso de apostilas e resolução de exercícios em aula, podendo indicar que tais práticas dos professores sejam, de certa forma, validadas por grande número desses estudantes. O fato de o professor não dar 
listas de exercícios foi apontado, em alguns relatos, como indicativo de uma "didática ruim".

No começo encontrei algumas dificuldades o que é normal, mas percebi que consegui aprender com as práticas dos exercícios. Pois o professor nos dava lista para fazer. E resolvendo as listas propostas eu consegui aprender (LM010/AB2).

Em alguns relatos essa didática "melhor" também aparece legitimada pela proposição de listas, uso de apostilas e resolução de exercícios. Dessa forma, questiona-se: o que é a Didática no contexto da aula de Cálculo 1? Ou melhor, existiria um Didática do Cálculo 1?

Marcas do trabalho educativo parecem sinalizar para a presença de uma "Didática do Cálculo 1" inserida na relação com a qualidade da exposição do professor de Cálculo 1; no foco nos conteúdos dessa disciplina; no fazer muitos exercícios ou a deixar que os estudantes os façam em aula; além dos procedimentos de passar listas de exercícios; corrigir essas listas e produzir apostilas de Cálculo 1.

Nessa direção, Reis (2001) questiona a impressão que os estudantes têm de terem aprendido o conteúdo ao conseguirem resolver exercícios; impressão essa que, para esse autor, parece compartilhada por muitos professores e autores de livros de Cálculo. No entanto, outros olhares são possíveis, assim como se considera válida toda proposta de inovação e tão pouco se desvaloriza as formas tradicionais de abordagens desse conteúdo.

Cabe assim uma reflexão mais intensificada na dimensão dessa relação de dialogicidade na qual professores e estudantes são termos de uma dialética delimitada nesse processo. Nessa via de mão dupla, aparentemente, sujeitos invadem espaços restritos a outros; espaços esses, que julgam conhecer, sem, no entanto, ocupar e entender o que é estar no lugar do outro. A ausência da alteridade parece prejudicar a experiência que poderia ser constituída de forma muito mais significativa nas aulas de Cálculo 1.

\section{O estudante e a instituição}

Para essas considerações, levou-se em conta as falas dos sujeitos que indicaram a Instituição como um elemento a interferir na passagem dos estudantes pela disciplina de Cálculo 1. Encontraram-se aspectos que ora colocam as contribuições da Instituição como adversas ao desenvolvimento e desempenho dos estudantes na disciplina, e ora como um elemento que, ao contrário, contribui para que os sujeitos não encontrem ou superem as dificuldades. Desse modo, ao propor esta unidade, considera-se a relevância da Instituição para o ingresso e permanência dos 
estudantes na universidade e, especificamente, no acompanhamento ao longo dos semestres iniciais como aluno de um curso na área de ciências exatas, etapa essa em que é ministrada o Cálculo 1. Em alguns relatos, esse canal de comunicação e relacionamento pareceu inexistente ou corrompido.

Destaca-se que a referência à Instituição foi de relativa significância em comparação aos outros aspectos apontados nas demais unidades textuais devido ao fato de pouco ter sido citada e em vista dos relatos em que apareceu implicitamente, mas houve uma recorrência e, portanto, os dados foram colocados em análise. Estudantes apontam para o choque de realidade que ocorre quando são confrontados com a matemática universitária.

$\mathrm{Na}$ abordagem 1, a Instituição foi apontada por 27 dos 186 estudantes investigados, de forma explícita ou implicitamente, como um elemento a contribuir negativamente em relação ao desenvolvimento dos estudantes em Cálculo 1. Em continuidade, na análise dos dados relativos à abordagem 2 , verifica-se que 23 dos investigados colocam na universidade um dos motivos de seu desempenho insatisfatório na disciplina de Cálculo 1, enquanto nenhum manifesta a relação com a universidade como algo positivo para seu próprio desempenho.

Conforme Bauman e May (2010), as próprias ações são pensadas tendo como modelo as ações dos outros, e para isso, sacam-se sempre de ferramentas explicativas, ou justificadoras. Desse modo, tornam-se perfeitamente comparáveis aos sujeitos, as ações da Instituição e os resultados de suas próprias ações.

Naturalmente, o modo como pensamos nossas ações é o modelo pelo qual damos sentido às ações dos outros. Nessa medida, a única maneira que temos para conferir sentido ao mundo humano à nossa volta é sacar nossas ferramentas explicativas estritamente no interior de nossos próprios mundos da vida (BAUMAM; MAY, 2010, p. 21).

Seriam os aspectos positivos inexistentes para a Instituição? A Instituição contribui apenas negativamente para a formação dos sujeitos? Cabe lembrar que as abordagens colocadas aos sujeitos requeriam que comentassem sobre a disciplina de Cálculo $1 \mathrm{e}$ sobre seu desempenho em Cálculo 1, portanto não foi solicitado que se remetessem à Instituição. Sem contar que, mais de $75 \%$ dos investigados não se manifestaram em relação à Instituição. Dessa forma, não se tem elementos para responder a tais questionamentos, além de que a Sociologia contribui para o entendimento da forma como se percebem as ações dos outros.

Tendemos a perceber tudo que acontece no mundo em geral como resultado da ação intencional de alguém, que procuramos até encontrar, acreditando, então que nossas investigações tiveram êxito. Assumimos que a boa vontade está por trás dos eventos para os quais somos favoravelmente predispostos e que há más intenções por trás daqueles que nos desagradam. Em geral, as pessoas têm dificuldade em aceitar que 
uma situação não seja efeito de ações intencionais de alguém identificável (BAUMAN; MAY, 2010, p. 22).

Outro aspecto apontado pelos estudantes e considerado nesta classificação diz respeito à organização da estrutura curricular dos cursos, como exemplo o fato de o Cálculo 1 ser disciplina de $1^{\circ}$ semestre em sete dos oito cursos citados nesta pesquisa, excluindo-se destes apenas o curso de Licenciatura em Matemática. E, nesse sentido, cabe destacar a referência ao grande volume de conteúdos programáticos listados nos planos de ensino.

É a disciplina que estuda funções, limites e Derivadas. [...] No caso das engenharias é apresentada no primeiro semestre ao aluno, causando às vezes um impacto e fazendo com que algumas pessoas até desistam do curso (EA004/AB1).

Um estudante do curso de Licenciatura em Física deixa transparecer sua impressão quanto à iniciativa da Instituição em oferecer uma revisão que considera necessária para reforçar a base matemática. Lembra-se, nesse sentido, que os conteúdos programáticos da disciplina de Cálculo 1 , comuns a todos os cursos que ofertam essa disciplina, constituem uma iniciativa institucional, obviamente corroborada pela comunidade docente.

A disciplina mostra primeiramente uma revisão sobre funções, gráficos de funções para então começar as Derivadas. Muitas vezes a falta de base do aluno em funções o prejudica [...] Alguns cursos disponibilizam a cadeira de pré-cálculo o que ajuda muito antes de começar cálculo 1, pois reforça a base sobre funções (LF010/AB1).

Os investigados imprimem também responsabilidade à Instituição quando sinalizam para a falta ou troca de professores durante o mesmo semestre. Sabe-se que é uma prática institucional recorrer à divisão da disciplina por mais de um professor. Acreditase, nesse sentido, que a divisão de uma disciplina por mais de um professor possa até trazer benefícios quanto às diferentes possibilidades de abordagens pedagógicas. Contudo, para alguns dos sujeitos pesquisados, esse procedimento é negativo.

Meu desempenho foi bom, também meu cálculo não foi muito completo, pois sofremos com trocas de professores ao longo do semestre. Tive dificuldade com limites, porém, Derivada e seus conceitos foi fácil (EC012/AB2).

Assim, não há como desviar-se de outras ocorrências também justificáveis pela Instituição, como o afastamento de um professor para tratar assuntos particulares ou de interesse institucional. Destaca-se ainda, o fato isolado da greve dos professores federais ocorrida em 2012, que também foi mencionado.

[...] Porém, durante a disciplina teve alguns contratempos, como a greve que interrompeu a disciplina no meio do semestre e a troca de professores durante o curso, mudando bastante o conceito de aula (LM007/AB1). 
Desse modo, até que ponto os estudantes estão informados acerca de ações que são institucionais, mas que implicam consequências diretas no desenvolvimento das aulas? Quando estudantes questionam a troca de professores, têm clareza dos motivos institucionais envolvidos? Acredita-se que a transparência e clareza das informações possam colaborar para a melhor continuidade dos processos de formação. Pensar sociologicamente é dar sentido à condição humana por meio de uma análise das numerosas teias de interdependência, que segundo Bauman e May (2010), são as árduas realidades a que se referem para explicar os motivos e os efeitos de suas ativações.

Em relação aos conteúdos programáticos, na Instituição em pesquisa, para as disciplinas comuns - Álgebra Linear, Cálculos I, Il e III, Cálculo Numérico, Equações Diferenciais, Geometria Analítica e Probabilidade e Estatística, há um plano oficial com a descrição dos conteúdos a serem cumpridos pelos professores que ministram essas disciplinas.

Quanto a esse fato, os estudantes em seus relatos utilizaram expressões que sinalizam para a dificuldade em vencer o conteúdo, deixando claro que o tempo de um semestre em aulas e o excesso de conteúdos pudessem ser motivos de suas dificuldades. A temporalidade da experiência implica a existência e o reconhecimento de tempos e espaços diferentes para cada sujeito da experiência, mesmo que tenham sido expostos aos mesmos estímulos e às mesmas situações em sua comunidade de experiência.

Fui bem em cálculo 1, tive mais dificuldades em limites, mas hoje sinto falta de ter tido mais tempo em aulas. Para quem tem dificuldades na área de exatas um semestre para cálculo 1 é pouco tempo (LF004/AB2).

[...] Sem essas "bases" o tempo disponível para vencer o conteúdo, tempo esse que já é reduzido, torna-se insuficiente para o aprendizado satisfatório do conteúdo (EC006/ AB1).

A disciplina de Cálculo 1 ministrada na Instituição em pesquisa possui uma carga horária de sessenta horas semestrais, alocadas em quatro créditos semanais. Pode-se aceitar que uma parte significativa dessa carga horária seja utilizada para o trabalho inicial com funções, ou seja, indicando que ocorra uma retomada de conteúdos relativos ao Ensino Médio, para depois adentrar a introdução ao Limite, restando algo em torno de $1 / 3$ do tempo semestral para a abordagem da Derivada. Assim sendo, se o trabalho com funções pudesse ser abreviado, talvez contribuísse para uma maior disponibilização para o estudo do Limite e da Derivada, melhorando o fator tempo para vencer o conteúdo. Contudo, como abreviar o trabalho com funções, sendo o objeto do Cálculo 1 justamente o estudo de funções, principalmente quando se tem evidências das defasagens dos sujeitos ingressantes em relação a esse conteúdo?

Admite-se também, a relatividade do tempo de cada docente para ministrar um determinado conteúdo, levando-se em conta aspectos como o perfil desse professor, 
dos vários alunos da turma, do próprio curso e até mesmo da Instituição.

Outra consideração que remete à Instituição tem relação com a oferta de um curso de "Pré-Cálculo". Vários estudantes apontaram esse curso como um suporte viável para o estudo de Cálculo 1. Contudo, verifica-se que a Instituição em pesquisa oferece com regularidade um de nivelamento para os ingressantes. No entanto, embora haja relatos sobre melhora de resultados por participantes nesses cursos, verifica-se também que a procura e permanência do estudante em cursos desse tipo é bastante restrita. Admitem-se os obstáculos que às vezes impossibilitam a participação de muitos estudantes, como o choque de horários com trabalho ou com outros componentes obrigatórios, no entanto, outros fatores podem estar contribuindo para que o estudante escolha não procurar, ou não permanecer no nivelamento até o fim.

Nessa direção, está a capacidade de comunicação entre a Instituição e os estudantes. Embora a Instituição mantenha um canal de notícias via internet, há evidências de sujeitos que, por falta ou dificuldade de acesso, não encontram informação a respeito de horário e funcionamento desses cursos.

Foi a minha insônia por dois semestres, no qual encontrei grande dificuldade por curso médio não me preparar, e na universidade não ter Pré-cálculo (EQ021/AB1).

Na Instituição em pesquisa, a oferta do Curso de Nivelamento/Pré-Cálculo ocorre regularmente, em geral, vinculada a um projeto de ensino implantado por professores do curso de Matemática. A oferta em geral é realizada em horários em que haja disponibilidade para os professores e bolsistas do projeto. Nesse sentido, pela incompatibilidade de horário, tem-se observado que a procura por esses cursos nem sempre compreende um número significativo de estudantes. Outro aspecto diz respeito aos estudantes que deixam de frequentar esses cursos, pois a partir do momento que encontram segurança em um determinado conteúdo, para o qual buscaram apoio, passam a dedicar-se a outras prioridades, pois já supriu a necessidade pontual ou mais urgente desse estudante. Nessa direção, a Sociologia tenta explicar no que se baseiam as escolhas voluntárias dos indivíduos.

[...] a escolha é voluntária porque o ator a praticou por livre opção, sem ser incentivado, empurrado, puxado ou tiranizado, nem o fez por hábito ou súbita irrupção de paixão. Ao escolher os cursos de ação por meio de deliberação consciente e racional, também se antecipa prováveis resultados. Isso exige o exame da situação real na qual a ação terá lugar e dos efeitos que com ela espera-se alcançar. Para tanto, normalmente leva-se em conta tanto os recursos disponíveis quanto os valores que orientam nossas condutas (BAUMAN e MAY, 2010, p. 100).

Volta-se também, a partir dos relatos de alguns sujeitos investigados, a atenção para o aspecto que diz respeito à adaptação desses estudantes nessa etapa de formação superior, pois conforme citado pelos sujeitos, ao ingressar na universidade, encontram 
um cenário diferente daquele vivenciado no Ensino Médio, além de vários outros problemas que se particularizam nas dificuldades vivenciadas por esses estudantes.

A primeira vez em que cursei a disciplina de Cálculo 1, ocorreram problemas familiares e precisei ir para a minha cidade de origem [...] (EP027/AB2).

É nesse turbilhão de novos fatos e de assumir novas responsabilidades que se deparam com a disciplina de Cálculo 1. Bauman e May (2010) contribuem acerca de fatores materiais que conformam a capacidade de se alcançar objetivos.

Apesar da importância do aspecto determinação, o que dizer se nos faltam meios para efetivar nossas decisões? [...] O que demonstramos aqui é o fato de que a liberdade de escolha não garante nossa liberdade de efetivamente atuar sobre essas escolhas nem assegura a liberdade de atingir os resultados desejados (BAUMAN; MAY, 2010, p. 33).

Um dos relatos se refere ao Cálculo 1 como um dos primeiros choques pelo qual os estudantes passam quando chegam à Universidade. Sendo considerado um dos "primeiros choques", significa que há outros, e a conotação da palavra choque permite considerar que haja indícios de desconforto e insegurança nessa relação.

A primeira vez que cursei foi quando ingressei, foi um choque a realidade da matemática universitária e a forma como o professor abordava os conteúdos e a impessoalidade, optei por desistir da disciplina [...] (LF002/AB1).

Nesse sentido, o papel da Instituição parece imprescindível para que nesse processo os acadêmicos tornem-se mais bem preparados e familiarizados com: a estrutura institucional; as questões administrativas e pedagógicas; as escolhas e opções de matrículas, diminuindo-se assim, uma possível sobrecarga no semestre. Inclusive, que sejam orientados por uma equipe multidisciplinar, no que se refere aos aspectos pessoais que também contribuem para a permanência com sucesso desses estudantes na Instituição e na cadeira de Cálculo 1, evitando-se desse modo, que grupos formais e informais se constituam pelas expectativas que lançam sobre os sujeitos, instalandose os hiatos de compreensão no interior dessa relação entre os estudantes e a Instituição. "Quando esses hiatos de compreensão se instalam entre grupos, costumam ser preenchidos por suposições estereotípicas" (BAUMAM; MAY, 2010, p. 34). Um exemplo disso, a certeza que muitos demonstram de que é "normal" a reprovação em Cálculo 1. 


\section{O estudante e o Cálculo 1}

Esta unidade textual diz respeito às considerações dadas pelos investigados que, ora os colocam como sujeitos para os quais o Cálculo 1 representou uma difícil travessia e pouco acrescentou em termos da especificidade matemática abordada; e ora como sujeitos para os quais essa disciplina oportunizou o encontro que deixa revelar a facilidade desse sujeito ao longo de seu desenvolvimento nessa disciplina, e que pode ter acrescentado o conhecimento novo esperado.

A partir do instrumento de coleta de dados, sugeriu-se que o estudante comentasse sobre a disciplina de Cálculo 1 e sobre seu desempenho nessa disciplina. Supunha-se que aspectos relativos aos conteúdos específicos do Cálculo 1 fossem levantados; no entanto, muitos relatos apontaram para aspectos subjetivos desse encontro. Surgiram termos como: "Disciplina assustadora"; "Vem como um susto"; "Foi minha insônia", "Os exercícios são difíceis"; "Tem muitas fórmulas"; "Há muito conteúdo". No entanto, os relatos dos estudantes foram marcados também por expressões positivas acerca de suas passagens pelo Cálculo 1, como exemplo: "Disciplina tranquila"; "Conhecimento básico para formação profissional"; "Aprovação"; "Revisão do Ensino Médio"; "Conteúdo fácil"; "Tive bom desempenho". A seguir, um fragmento do comentário feito por um estudante da Engenharia de Produção, ilustra esse fato. Do comentário, destacamse as palavras: "calma" e "tranquilidade", e o aspecto positivo evidenciado na relação desse sujeito com a disciplina de Cálculo 1.

Há indícios de que para esse sujeito, a passagem pelo Cálculo 1 possa ter deixado marcas relativas às especificidades do conhecimento em construção, pois o mesmo pondera que levou consigo uma grande carga de conhecimento.

[...] Passei com calma e tranquilidade pela disciplina, trazendo comigo uma grande carga de conhecimento. Me saí bem nas provas e no final passei com muita tranquilidade na disciplina (EP001/AB2).

Porém, nos relatos pouco ou quase nada foi dito a respeito da especificidade de conteúdos geralmente abordados em aulas de Cálculo 1. Em algumas falas houve alusão aos tópicos mais gerais, listados como um rol de conteúdos, tais como: Funções, Limite e Derivada, o que pode sinalizar para o formato em que se lhes apresentou o Cálculo 1, ou seja, a ordem praticamente solidificada iniciada pelo estudo de Funções, seguido de Limite e finalizado em Derivada.

Assim como apontado nas análises das demais unidades, sobressaem-se os aspectos que se contrapõem e também se complementam a partir dos relatos dos investigados. Apontam-se assim duas palavras recorrentes que dão sentido às vezes contraditório ou de certo contrassenso às expressões dos sujeitos, são elas: "reprovação" e "aprovação". A palavra aprovação parece representar sentimento de satisfação, de autoestima 
elevada, indicando assim que ser "aprovado de primeira" carrega em si uma conotação positiva perante colegas e professores.

Como sou um privilegiado de ter passado na primeira vez que fiz, posso dizer que o meu desempenho foi bastante satisfatório. Me deu uma boa base para o Cálculo II, posso ficar contente por ter aprendido limites, e principalmente Derivadas, assim como posso falar que domino Derivadas, tenho certeza que minha passagem pelo Cálculo I não foi em vão, pois até agora não estou com dificuldade em Cálculo II, acredito que foi pelo bom desempenho que tive em Cálculo I. Para finalizar vou dizer que: fiquei muito satisfeito com o meu desempenho, pois como já falei estou em um grupo seleto de poucos que conseguiram vencer a disciplina na primeira vez que cursou a mesma (LM013/AB2).

Ser reprovado, entretanto, significa a negação de tudo isso. Se o fato, aprovado em Cálculo 1 e de "primeira", pode representar muito mais do que uma etapa vencida na formação desses sujeitos, ser reprovado na primeira, segunda, ou terceira vez, pode ser a causa de inseguranças e desistências. Um dos estudantes na abordagem 2 escreveu apenas "Fui aprovado na $1^{\text {a }}$ tentativa" (EP029/AB2), e de fato, para muitos, somente isso basta.

Contudo, em alguns casos, embora aprovados "de primeira", os estudantes externaram insegurança e atribuíram à aprovação, ora o fator sorte, ora o fato de ter decorado o conteúdo, ora o seu empenho pessoal, além de outros aspectos que revelam um desempenho mediano por parte desses sujeitos. Consideraram ainda que o conteúdo de Cálculo 1 é bastante complexo e requer o conhecimento anterior, referindo-se ao Ensino Médio - principalmente ao conhecimento de Funções, e aplicação de muitas fórmulas, além de muita dedicação para fazer os exercícios propostos nas listas.

Foi uma das disciplinas que mais penei para ser aprovado e mesmo assim considero despreparado para enfrentar outras cadeiras que utiliza o conhecimento de cálculo 1 , pois às vezes a maneira como o professor explica que a torna mais complicada do que já é, mas creio que o conteúdo é um conteúdo um tanto difícil também (ER012/AB2).

A expressão "fórmula" apareceu sempre acompanhada de uma conotação negativa.

Disciplina que pra mim foi bastante difícil. Acho um tanto complexo o conteúdo, [...] A disciplina em si é composta por muitas fórmulas, o que já traz mais uma dificuldade. Sabê-las e saber aplicá-las (EP014/AB1).

Na primeira vez o Cálculo I, a dificuldade foi em relação a limites e Derivadas, alguns conceitos me eram difíceis de entender, porém, funções, por ser um conteúdo já visto na escola, consegui entender perfeitamente. Na segunda vez, função e limites foram relativamente fáceis, porém devido muitas regras e fórmulas na Derivada, no meu foi um pouco complicada (EQ020/AB2). 
Parece persistir em alguns relatos o aspecto contraditório nesse aspecto, contudo é complementar, pois trata de momentos distintos desse estudante no Cálculo 1. Por exemplo, o estudante menciona sua dificuldade na disciplina em um primeiro contato, e nesse sentido, pode tal fato significar que se deparou com o conhecimento novo. Em uma segunda vez no curso, ao considerar por si próprio que encontrou facilidade, admite-se que esse sujeito pudesse ter construído alguma percepção dialógica com algo já iniciado anteriormente, pois a relação entre sujeito e objeto agora ocorre diante do revivido.

Em um primeiro momento encontrei dificuldade tanto que acabei reprovando na disciplina. No segundo semestre já conhecendo a matéria e trazendo algum conhecimento anterior não encontrei dificuldade e passei para o cálculo II (EP013/AB2).

Nessa direção, a reprovação para alguns estudantes se apresenta como base de um processo de amadurecimento, e não poderia significar algo negativo ou angustiante.

Bem, a disciplina de Cálculo 1, na primeira vez em que cursei, me pareceu bem difícil, por nela conter conceitos por mim jamais vistos em matemática. De início começando com tipos de funções, pareceu-me até fácil, mas quando começou a se falar de limites, limites laterais, limites infinitos e Derivadas, entrei em colapso. Entretanto, quando o fiz pela segunda vez, ele não parecia tão assustador assim, já tinha respostas na ponta da língua, e precisei "estudar" bem menos do que a primeira vez. Enfim, acho até que gostei de repetir Cálculo 1, pois saí dali aprendendo fielmente tudo que a disciplina me proporcionou (LM006/AB1).

Salienta-se assim a concepção de conhecimento prévio ${ }^{3}$, pois em uma segunda vez cursando a mesma disciplina, a familiaridade com determinados conceitos já vistos pode ter permitido essa "maior facilidade" no aprendizado desses estudantes. Conforme alude Ausubel (2003), conhecimento prévio é definido em função de uma mudança, na qual certa estrutura cognitiva inclusiva pré-existente está em relação a um novo conhecimento; no processo de ressignificação desse conhecimento, ambos, estrutura prévia e conhecimento novo, são modificados e se influenciam mutuamente durante a experiência de aprender significativamente.

Outro aspecto que se destaca nos relatos diz respeito ao fato de o estudante considerar a disciplina de Cálculo 1 importante para sua evolução no curso, mencionando que essa disciplina serve como base para cursar os outros Cálculos ou outras disciplinas, contudo, poucos foram os sujeitos que se referiram à importância do Cálculo 1 para o exercício futuro de sua profissão.

3 Considera-se que os conhecimentos prévios dos alunos são formados no "predomínio do perceptivo, no uso do raciocínio causal simples, na influência da cultura e da sociedade (canalizadas através da linguagem e dos meios de comunicação), influência da escola" (POZO, 1998, p. 88). E, em Pozo e Gomes Crespo (2009), essas causas são classificadas em três grupos que dão origem a diferentes concepções prévias: origem sensorial (concepções espontâneas); origem cultural (concepções induzidas); e origem escolar (concepções analógicas). 
A disciplina de Cálculo 1 dá o start ao aluno. É uma das matérias mais importantes em toda a estrutura acadêmica, tendo em vista que ela é a base para o restante do curso (EQ014/AB1).

A cadeira de Cálculo 1 é o primeiro "back" ao entrar na vida acadêmica, pois vem o temido limite, Derivada e suas teorias. Mas para passar pro Cálculo 2 é necessário saber entender e não decorar as regras e exercícios (EQ008/AB1).

Os estudantes, em geral, não demonstram relação entre o Cálculo 1 e sua formação profissional. Apenas o apresentado no fragmento de (LM010) citou a importância do conhecimento específico sobre funções e Derivadas para o exercício docente.

É uma disciplina que permite ampliar nossos conhecimentos sobre funções e Derivadas. Sendo assim de suma importância para nós, futuros docentes (LM010/AB1).

Cabe destacar expressões encontradas nos relatos dos investigados e que trazem consigo uma conotação positiva, como anteriormente mencionado em relação à palavra aprovação, tais como: dificuldades superadas; motivado; disciplina mais amada. Desse modo, pode-se permitir inferir que os sujeitos passaram pelo Cálculo 1 encararam as primeiras dificuldades e foram capazes de avançar com relativa segurança. E essas seriam marcas importantes da passagem por essa etapa de formação - marcadas pela capacidade de resiliência.

Contudo, em outros relatos, os sujeitos também dão exemplos de palavras e expressões que revelam o aspecto negativo pelo qual "observam" o Cálculo 1, tais como: disciplina assustadora, temida, insônia, colapso, na primeira vez foi lunático. O fragmento do relato de (EC004) exprime os dois extremos na mesma resposta.

Acredito que seja a disciplina mais amada e odiada ao mesmo tempo (EC004/AB1).

Parece que o Cálculo 1 desenha um capítulo bipolar na formação dos sujeitos, e nesse sentido contribui Balman e May (2010) ao referir-se à alma humana.

Amor e troca são dois extremos de uma linha contínua ao longo da qual todas as relações humanas podem ser alocadas (BALMAN; MAY, 2010, p. 147).

Ao se referirem a sua passagem pelo Cálculo 1, os estudantes deixam transparecer aspectos angustiantes desse encontro, assim como aspectos motivadores. Nesse sentido, nesse jogo de sentimentos contraditórios, o que deixam revelar de suas experiências, de suas marcas? A experiência, assim, se abriga nos aspectos subjetivos, reflexivos e transformadores capazes de revelar elementos constitutivos dessa passagem. 
É em mim (ou em minhas palavras, ou em minhas ideias, ou em minhas representações, ou em meus sentimentos, ou em meus projetos, ou em minhas intenções, ou em meu saber, ou em meu poder, ou em minha vontade) onde se dá a experiência, onde a experiência tem lugar (LARROSA, 2011, p. 6).

Uma questão final se sobrepõe nesse estudo, pois bem maior que o volume de aspectos positivos apontados nos relatos, são os aspectos relacionados a sentimentos negativos. Nesse sentido, podem ser esses últimos as principais marcas deixadas pelo Cálculo 1? Esperava-se que os estudantes, independentemente da qualidade negativa ou positiva de sua percepção, quando solicitados a comentar sobre Cálculo 1, falassem de sua estrutura curricular, ou acerca de um tópico estudado nesse componente. Da mesma forma, quando solicitados a comentar sobre seus desempenhos, era esperado que mencionassem suas dificuldades ou facilidades, ainda que essas estivessem vinculadas a uma abordagem específica do conteúdo dado na disciplina, como por exemplo: à dificuldade em compreender o conceito de Derivada, ou à dificuldade em resolver um problema envolvendo taxa relacionada, ou em analisar e elaborar o gráfico de uma função, entre outros.

No entanto, os relatos apontaram superficialmente para dificuldades específicas do Cálculo 1 e, mais fortemente, para expressões subjetivas e negativas que parecem deixar marcas indeléveis na vida acadêmica desses estudantes.

O sujeito da experiência tem algo desse ser fascinante que se expõe atravessando um espaço indeterminado e perigoso, pondo-se nele à prova e buscando nele sua oportunidade, sua ocasião. [...] Não um sujeito que permanece sempre em pé, ereto, erguido e seguro de si mesmo; não um sujeito que alcança aquilo que se propõe ou que se apodera daquilo que quer; não um sujeito definido por seus sucessos ou por seus poderes, mas um sujeito que perde seus poderes precisamente porque aquilo de que faz experiência dele se apodera. Em contrapartida, o sujeito da experiência é também um sujeito sofredor, padecente, receptivo, aceitante, interpelado, submetido (LARROSA, 2011, p. 25).

Se nada ou pouco lembram sobre os conteúdos específicos do Cálculo 1, então a experiência desses estudantes pode estar se consolidando fortemente marcada por esses sentimentos tomados de negatividades.

\section{Considerações finais}

A experiência, embora livre, tem sentidos. Cada sujeito da experiência exposto neste estudo deixou revelar dimensões da dialogicidade ocorrida em aulas de Cálculo 1. A reciprocidade é um dos princípios para que a experiência dos sujeitos em Cálculo 
1 ocorra em relação à apropriação do conhecimento novo, aquele que modifica o que está posto. Não se imagina a interação restrita a conteúdos, mas aquela que engloba os conteúdos e os sujeitos da experiência como elementos dessa interrelação.

Nesse sentido, concorda-se com a possibilidade de que a dificuldade dos estudantes frente ao Cálculo 1 possa estar na Matemática, mas não em um conteúdo restrito da área. Assim como ações pontuais com a finalidade de resolver um ou outro foco específico dessa problemática possam não ser suficientes. É preciso que compreenda uma atitude assumida e coordenada coletivamente e que surja da corresponsabilidade dos sujeitos envolvidos nesse processo de construção de conhecimentos, consideremse corresponsáveis estudantes, professores e instituição.

Alguns estudantes investigados apontaram que, por meio de suas capacidades criativas, contribuíram em favor de sua adaptação e sucesso frente ao Cálculo 1. A fim de superar os obstáculos, demonstraram características de um sujeito corresponsável e resiliente. Todavia, muitos apresentaram suas justificativas e fugas do mesmo problema, revelando um processo particular de escolhas e de fatores limitadores dessas escolhas, razões puramente sociológicas impostas aos indivíduos quando tomam suas decisões, quando elegem suas prioridades. Novamente, não se descarta dessa alusão a corresponsabilidade, e com isso a igual parcela que cabe ao professor, ao comprometer-se e assumir o importante papel de conduzir os processos de ensino e aprendizagem.

Cada estudante reage de uma forma única diante do Cálculo 1, que é inidentificável e imprevisível ao professor. Evidenciam-se, nessa dialogicidade, as dimensões das incertezas. Nesse cenário, estudantes classificam o "bom" professor de Cálculo 1. Identidades se constituem nessa relação. Em torno da reciprocidade, Bauman e May (2010, p. 60) apontam para o lado assimétrico dessa interação, "ao longo de períodos abrangentes, as ações de ambos os lados se contrabalançam, porque cada um tem a oferecer algo de que o outro lado precisa". A existência desses conflitos indica que essas identidades estão em jogo. Alcançar o conhecimento de um objeto matemático requer o diálogo entre essas identidades, diálogo esse que é imprescindível à consolidação da experiência esperada em torno do ensino e aprendizagem do Cálculo. 


\section{Referências}

Bardin, L. (2009). Análise de Conteúdo. 5. ed. Tradução Luís Antero Reto e Augusto Pinheiro. Lisboa, Portugal: Edições 70, LDA.

Barufi, M. C. B. (1999). A construção/negociação de significados no curso universitário inicial de Cálculo Diferencial e Integral. 184 p. Tese (Doutorado) Faculdade de Educação da Universidade de São Paulo, SP, Brasil.

Bauman, Z. (2001). Modernidade Líquida. Tradução Plínio Dentzien. 1. ed. Rio de Janeiro: Jorge Zahar.

Bauman, Z. \& May, T. (2010). Aprendendo a pensar com a Sociologia. Tradução Alexandre Vieira Werneck. 1. ed. Rio de Janeiro: Jorge Zahar.

Bogdan, R. C. \& Biklen, S. K. (1994). Investigação Qualitativa em educação. Tradução Maria João Alvarez et al. 1. ed. Porto: Porto Editora.

Dall'anese, C. (2006). Argumentos e Metáforas conceituais para taxa de variação. 131 p. Tese (Doutorado em Educação Matemática) Pontifícia Universidade Católica de São Paulo, São Paulo, SP, Brasil.

Freire, P. (1979). Ação cultural para a liberdade. 4 ed. Rio de Janeiro: Paz e Terra, 1979.

Garzella, F. A.C. (2013). A disciplina de Cálculo I: análise das relações entre as práticas pedagógicas do professor e seus impactos nos alunos. 259 p. Tese (Doutorado em Educação) Universidade Estadual de Campinas, Campinas, SP, Brasil.

Junqueira, S. M. S. (2010). Constituição da identidade de cursos de Licenciatura em Matemática à luz da modernidade líquida. 238 p. Dissertação (Mestrado em Educação: Matemática) Pontifícia Universidade Católica de São Paulo, São Paulo, SP, Brasil.

Junqueira, S. M. S. (2014). Experiências de estudantes na construção do conhecimento de derivada em aulas de cálculo 1.213 p. Tese (Doutorado em Educação: Matemática) Pontifícia Universidade Católica de São Paulo, São Paulo, SP, Brasil.

Junqueira, S. M. S. \& Manrique, A. L. (2012). As subjetividades no desenvolvimento de competências matemáticas do futuro educador matemático. Simpósio Internacional de Pesquisa em Educação Matemática - SIPEMAT. Anais... Fortaleza, CE, Brasil. 
Larrosa, J. B. (2011). Experiência e Alteridade em Educação. Revista Reflexão e Ação. $19(2), 4-27$.

Pozo, J. I. (1998). Teorias cognitivas da aprendizagem. [3 ed]. São Paulo: Artes Médicas.

Pozo, J. I. \& Gómez Crespo, M. A. (2009). A Aprendizagem e o ensino de ciências: do conhecimento cotidiano ao conhecimento científico. Trad. Naila Freitas, [5 ed]. Porto Alegre: Artmed.

Reis, F.S. (2001). A Tensão entre Rigor e Intuição no Ensino de Cálculoe Análise: a visão de Professores-Pesquisadores e Autores de Livros Didáticos. 302 p. Tese (Doutorado em Educação). Programa de Pós-Graduação em Educação. Universidade Estadual de Campinas, Campinas, SP, Brasil.

Rezende,W.M. (2003). OEnsino de Cálculo: dificuldades de natureza epistemológica. 468 p. Tese (Doutorado em Educação) Programa de Pós-Graduação em Educação. Área de Ensino de Ciências e Matemática. Faculdade de Educação da Universidade de São Paulo, São Paulo, SP, Brasil.

Silva, B. A. (2011). Diferentes dimensões do ensino e aprendizagem do Cálculo. Educ. Matem. Pesq. 13(3), 393-413.

Vieira, A. F. (2013). Ensino de Cálculo Diferencial e Integral: das técnicas as humanswith-media. 204 p. Tese (Doutorado em Educação). Programa de Pós-Graduação em Educação. Área de Concentração: Ensino de Ciências e Matemática. Faculdade de Educação da Universidade de São Paulo, São Paulo, SP, Brasil. 